\title{
THE DEVELOPMENT OF THE MODERN WORLD IN THE ASPECT OF NEW TECHNOLOGIES
}

\author{
Katarzyna ZAWIERUCHA \\ Faculty of Command Management, War Studies University, Warsaw, Poland; \\ k.zawierucha@akademia.mil.pl, ORCID: 0000-0002-9439-5589
}

\begin{abstract}
Purpose: The article focuses on defining the concept of new technologies as well as presenting selected technologies that have a significant impact on reality. The aim of the article is to draw attention to the phenomenon of the increase in the importance of robots and artificial intelligence and presenting the opportunities for world development resulting from the escalation of the phenomenon of creating new technologies and threats to the development of the modern world in the context of these technologies. As a result, the rapid development of the modern world was assessed.
\end{abstract}

Design/methodology/approach: The results of the analysis allowed to determine what the main technologies dominate the life of society and determine to what extent a person is able to give up their personal data for comfort.

Findings: The article shows the essence of new technologies in the modern world and the direction and speed of its development in this aspect. The article defines the impact of new technologies on social reality and provides a general analysis of new technologies and artificial intelligence. The information contained in the article determines the importance of new technologies and their autonomy in social life, and indicates the level of comfort in the loss of privacy.

Originality/value: The information contained in the article defines the concept of new technologies and presents selected technologies that have a significant impact on reality.

Keywords: new technologies, artificial intelligence, people-robots, opportunities and threats to the development of the world.

Category of the paper: review publication.

\section{Introduction}

The progress of civilization and the creation of novum in a very short time affect the changes and continuous development of the modern world. This dynamization has created the idea of analyzing a few selected technologies that most affect social reality. The argument for the topic was the topicality and relevance of new technologies directly affecting the development of the 
modern world, as well as showing the opportunities and threats resulting from the phenomenon of the escalation of modernity.

Technological changes that have taken place over the past years and continue to occur make it possible to communicate more efficiently, taking into account both transport means and interpersonal communication, information exchange and access to it. New technologies give the opportunity to easily access knowledge and culture, to manage time more efficiently by using services without leaving your home. New technologies are also intelligent machines that improve and help people in action. It is important, however, to properly use what modernity offers. New technologies guarantee the flow of data in all parts of the world, an increase in the level of comfort of life, a reduction in the number of duties and an increase in ease of existence. Proper use of new technologies means rapid development, access to entertainment, knowledge fields, and networkingmand increased security.

However, there is also the other side of new technologies, which is conducive to the spread of dangers lurking even in the network. Young people who are not aware of the problem, people vulnerable to addictions and those who face environmental rejection are most exposed to these dangers.

Threats that new ones bring technologies can cause irreversible effects, loss of profession, loss of intelligence, loss of contact with reality or death resulting from addiction, errors in the functioning of devices or ethics of people responsible for creating technology.

Each epoch brings its own revolutions, interesting discoveries and valuable technologies. Modern times provide many new discoveries. Probably artificial intelligence, which is a new technology of the modern world, is the latest invention of humanity. It will take over ten or several dozen years before super artificial intelligence reaches every human being, at present a part of society is not yet sufficiently prepared to know new things and often unconsciously falls into various dangers, some do not show a willingness to learn what progressive while the others who demonstrate the right approach use what they offer new technologies.

The main goal of the article is to identify new technologies, present selected technologies, verify the opportunities and threats resulting from the creation of these technologies, and present and describe the problem of development of the modern world in the dimension of new technologies. In pursuit of the assumed goal, new teologchnies, artificial intelligence, people-robots were defined, basic technological benefits and concerns were presented, their essence was presented, the problem was analyzed and the impact of new technologies on society and the world was determined, and the speed of the mentioned development was also emphasized. 


\section{The concept of new technologies}

Technology in its basic definition means the field of technology that deals with the design and modeling of new production methods or processing methods for raw materials. Thus, new technologies mean using these latest results resulting from learning about science in connection with the conducted research and applying them in practice (Group work, 1996).

The development of new technologies radically changes the lives of citizens and influences the changes taking place in the economy. The service providers base their activity on various types of mobile applications, facilitating access to customers and limiting papirology and formalities. New technologies are designed to bring people to a better tomorrow, to match the most developed countries, broaden horizons and increase the standard of living. This is possible thanks to globalization, which means that modern technologies have no limits. Each new technology is consequently available on every continent.

New technologies undoubtedly have the greatest importance on the economic market. They directly connect with information technology (IT), which allows the processing of information between devices and users of these devices. Additionally, it stores and protects the information obtained, for subsequent analysis and presentation, so that the right information can be delivered to people. The new technologies market in cooperation with IT is developing at an alarming rate. Human is able to identify most of the technology, but he does not quite know it. Often people are unable to keep up with constant changes and development. New motor vehicles, virtual reality, smartphones are basically today's reality.

Technology never stands still. Its development is extremely significant in all times, especially in today's, where the level of development reaches its end. Technology adapts and develops along with human development. Today, human is not yet ready for super artificial intelligence, but he will be fully prepared in several dozen years. Like the, things that seemed impossible to implement today are at hand.

Everyone is part of new technologies and artificial intelligence, and everyone builds them, without asking questions and without knowing about the consequences. Social networks, mobile applications and devices together with people constitute a cybernetic set. This collection is often not applicable to older people who, due to the huge amount of information contained in the virtual world and the service of these devices have difficulty with efficient use of it.

Cyberspace, which is permanently associated with new technologies, is treated as an extended social space that often becomes a reality or a second life. Cyberspace is an illusion of the real world, an imaginary world created with the help of teleinformation tools (Retkiewicz, 2013a).

The word cyberspace was first used by American science fiction writer William Gibson in 1984. He defined cyberspace as a space created in the memory of computers. According to the author of the definition, cyberspace gives the possibility of a sense of balance, an escape from 
constant changes, as well as a place of escape for individualists who feel safe in cyberspace. Gibson believed that the two worlds, the real and virtual world, permeate each other, and people can move freely between these worlds. In the novel "Neuromancer" he called cyberspace "Collective hallucination, experienced every day [...] Graphic mapping of data downloaded from the banks of all computers in the world [...] Lines of light wandering in the cells of the mind and data constellations. Like the light of a distant city" (Retkiewicz, 2013b).

The author was right because devices connected to the network accumulate a huge amount of data and this is about the human community, which lives in two worlds or only in the virtual one.

Each generation, thanks to knowledge and experience, own and those acquired by their predecessors and through new inspirations and attempts to achieve the impossible, transcends the old boundaries and sets new horizons. Every society creates its social reality, which is treated as the world of everyday life. The world that is created in minds and actions, and then, thanks to these thoughts and actions, functions in the real Word (Berger, Luckmann, 1983). Artificial intelligence is created, robots replace people. All intentions can only be realized if it is commensurate with the current level of technology.

The rapid development of technology causing blurring of reality caused many dangers. Through computerization, new technologies and artificial intelligence introduced to all economic sectors, as well as the collection of data in IT systems, the ease of access to these data was born. The dynamic development of the real and virtual world has resulted in the possibility of numerous benefits. However, despite positive aspects, digitization has brought with it new forms of threats.

The rapid development of technology causing blurring of reality caused many dangers. Through computerization, new technologies and artificial intelligence introduced to all economic sectors, as well as the collection of data in IT systems, the ease of access to these data was born. The dynamic development of the real and virtual world has resulted in the possibility of numerous benefits. However, despite positive aspects, digitization has brought with it new forms of threats.

The development of computerization has made every password possible to "break" and the prospect of not being able to exchange information generates huge problems. In addition, an artificial intelligence has developed that is able to create its own artificial intelligence. Whether in the near future there is still room for a human? Humanity has given direction to development, which may prove fatal.

As a result of initial arrangements and predictions, the reality that was intended to improve security, communication, cooperation and human comfort throughout the world proved more useful to criminals, affected the decline of human intelligence, escalation of terrorism and future cyber wars. 


\section{Selected new technologies}

All new technologies influence and create reality. However, there are those that have a major impact on or will affect future life and society. The basic technology that affects most devices is the Internet of Things. According to this concept, devices and objects collect or exchange acquired and reconstructed information. This is possible due to the sensors they have and via the computer network to which they are connected. The Internet of Things creates communication without human participation. Devices, applications, etc. communicate in their own language. Objects connected to the Internet can also be controlled by a human using a smatrtphone, eg intelligent light bulbs connected to the network can be switched on and off remotely.

The Internet of Things is also smart refrigerators or their equipment. A prosaic example is here, for example, an intelligent container for eggs, which, thanks to cooperation with a smart-phone, gives you the opportunity to check your content while shopping. Smartphones are the basis of the Internet of Things, because with him the person is practically parting. Smartphon knows when a person returns home, thanks to the location application enabled, he knows where a given person should be at a given time and place by information stored in embedded electronic calendars, when someone goes to sleep because then the screen smatfona does not turn on every now and then.

The Internet of Things, in addition to ordinary, everyday activities, is also used in the main branches of the national economy: in trade, transport, industry, science, enlightenment, health care, administration and other services. The Internet of Things has found its application also in agriculture, where it is used to check the quality of cereal grains, fertilizers and fodder. It is used for integration of producers 'and recipients' systems, with the help of machines controls watering and crop fertilization.

Innovative solutions used by the Internet of Things do not cause that human life changes dramatically, they are aimed at helping and saving time, but at the same time they "take away" people's work and the time mentioned above.

Another new technology created by human are autonomous cars, also known as unmanned cars. These are computer-controlled vehicles that have been programmed by human. However, these cars remain autonomous to their creators because their artificial intelligence makes autonomous means of transport learn each other.

Autonomous cars are a vision of the near future, although in some countries they have already found their application. They serve as taxis, or vehicles supplying food ordered from a take-away restaurant or from online shop.

There is a high risk that autonomous vehicles deprive many people who just keep themselves and their families by the profession. This is definitely a big economic problem, but it does not mean that these cars will only destroy the labor market. Autonomous motor 
vehicles can help at work and replace people in specific situations. Their advantage is that these cars do not get tired, do not lose their concentration, do not fall asleep unlike people, and yet they can fail.

The basic dilemma of autonomous cars is the ethics of the creators of these cars. Depending on how they were programmed and what they learn, they will react in this way. If the car is programmed to cause harm to someone, it will behave like this, for example, provoking an accident. Another problem is to decide how the car should react in the event of a possible crash with another vehicle or driving in the column of pedestrians or cyclists, whether the car should protect its own passenger or other people. Cars that are allowed to be used are probably designed to protect others. There are also no escapes from such dilemmas in regular motor vehicles.

Autonomous vehicles do not only apply to passenger cars, but also to rail vehicles, buses and lorries. They are also used to control water reservoirs as autonomous sea vessels or in the army as autonomous tanks and armed tactical robots. It is also worth mentioning that in aviation, autopilots have been used for a very long time, performing fixed tasks, automatically controlling the airfield.

It is likely that in the future the society will not have a document entitling them to drive motor vehicles. Some people believe that possession of a driving license will be forbidden in the future. However, it seems impossible in the near future. Autonomous cars should not take people's work just like automated devices in production plants, they can only change the type and nature of the work performed. In addition, autonomous cars can support drivers and, in the event of fatigue, take control. The advantage of such cars is also the fixed speed of movement compared to the variable speed of movement of the society in motor vehicles. However, this leads to the loss of intelligence and the limitation of thought processes.

The intelligent house (IQ-Building) is a building equipped with a modern system and technology. The intelligent home works thanks to the connection of the building with integrated control installations of various home appliances. An intelligent home is centrally managed by a human, using a smartphone or works automatically through mounted sensitive sensors, eg on light or human steps. It is possible by combining separate operating systems with each other, which limits their continuous control.

An intelligent home can be managed locally or from anywhere in the world, in which there is access to the Internet. This regulation is characterized by high security, and the transmission of transmitted data is secured by a 192-bit encryption key, i.e. very similar to the security of banking transactions.

IQ-Building is a solution thanks to which you can feel safe. When a large amount of smoke accumulates in the room, automatic airing takes place, the lights start to blink and the smart house sends emergency messages to predefined telephone numbers. 
An intelligent home is also a possibility of saving resulting from continuous media measurement, systemic extinguishing of lights, when no-one is currently in the room, lowering the temperature and switching off the air-conditioning. Additional features of a smart home include:

- signaling the opening of windows and doors,

- automatic lighting control,

- modern control panels, e.g. to reveal/cover the window blind,

- integrated garden irrigation,

- mode exit from home (alarm arming),

- a gate controlled by long car lights,

- remote control of windows, as a result of atmospheric changes,

- algorithms that use twilight sensors to turn on the light, closing the house,

- configurable response to door opening - automatic switching on of lights,

- reaction to detection of presence - lighting appropriate spaces, starting night modes.

How do you live with a smart home system? Is such a life more comfortable and safe or inhibits human development? Maybe soon you will be able to experience it yourself.

Unmanned aerial vehicles, also known as drones, are a new technology that is growing very fast. Drones are airplanes that are controlled remotely or automatically, do not require crew, they do not have space to take people aboard. Unmanned aerial vehicles were created to monitor, control and filter objects. They found their application in everyday life and in the army, where they are used to:

- diagnosis,

- object tracking,

- securing humanitarian missions,

- building inspections,

- border security,

- archiving,

- searching for improvised loads,

- securing real-time operations,

- securing the camp,

- help with setting roads.

In Poland there is the 12th Base of Unmanned Aircraft in Mirosławiec, whose task is also to save human beings, eg from places of danger. These ships have weapons and can carry out combat operations.

Unmanned aerial vehicles have more and more applications. They are also used to control chimneys, to check the chemical composition of the chimney, to check what residents tanning their homes. Drones are also used in agriculture, for crop monitoring. In transport, for some time now they have been used to distribute shipments, to private homes with a designated 
landing place for the drone. Special parcel locks are created for the block's residents, in which the unmanned aerial vehicle will be able to leave the parcel. In addition, in the largest city of the United Arab Emirates, drones are already being created that will be able to transport people, and every transport drone will be equipped with a parachute.

Furthermore, unmanned aerial vehicles are to be an Intelligent Transport System in order to control cities in an innovative and problem-free manner. Drones will be tasked with checking traffic, controlling air quality and weather, supervising whether road users are complying with regulations, serving as a modern monitoring.

In some cities, eg in Barcelona, Intelligent Transport System uses smart meters to optimize electricity consumption, garbage containers with sensors for filling them (optimizing the waste disposal route, thereby minimizing costs), parking spaces equipped with sensors monitoring free spaces or the possibility of reserving the parking lot remotely (restricting traffic jams, reducing fumes), street lamps with access to the network for controlling, e.g. air quality and those that darken the light if no one is currently moving with a illuminated road or sidewalk.

There is no doubt that the multitude of drones or other devices monitoring the city can evoke enormous impressions and provide a lot of information, but also take privacy by tracking every step.

Another new technology that can soon become an everyday reality is home printing. Houses are printed using a 3D spatial printer. Object designs are created by computer as threedimensional objects, and then spatially printed. Using a 3D printer, you can print ready-made objects or individual parts of given objects. China is the leader in printing houses, which can print as many as ten houses in less than a day. Home printing is also being done by the United States, and in Europe - the Netherlands, or indeed its capital. In Amsterdam, however, each room is printed separately and combined in different configurations.

Printing houses is a very important technology for countries touched by frequent natural disasters. In the event of a flood, fire, earthquake or hurricane, residents affected by the disaster will be able to quickly print and live in new house.

Many objects can be printed using 3D printers, but there is a risk that they will be misused. Nowadays, there are situations where a weapon is printed using a spatial printer that can be used in armed combat and be used for the wrong purpose. You do not need a permit for such a weapon, and they perform the same functions as weapons produced in weapon factories.

Solar signs, or road signs powered by solar energy, are a recent technology that already works in some cities. Sunny signs are a good solution for places where it is not possible to connect the installation to the mains or it is very expensive to connect. In addition, road signs powered by solar energy are very visible at night (providing safe driving), reduce greenhouse gas emissions and dissolve snow. It is also important that such signs have found their application also in Poland, where the climate is not very favorable. This means that they are able to accumulate a large amount of solar energy (IH, 12.12.2018). 


\section{People - robots}

What will the world look like when the boundaries between people and robots start to blur or when robots start to replace people and, as a consequence, take over the world? Will a man be considered a ruler or deity by a robot? Will a man, like a monkey, be dominated by a robot? At the moment, there are no answers to these questions, every man can make his own reflections. However, the huge role of robots that they already play and will play in the life of society seems to be unavoidable. Observing the surrounding reality, it should be stated that more and more often people are starting to reach for various types of robots: kitchen robots, vacuum cleaners, automatic washing machines, automatic dishwashers, automatic lawn mowers, technically advanced toys, or even ATMs, all the robots that make decisions. Nobody is able to stop the development of new technologies. It is surprising that every novelty comes at the right moment, not too early and not too late, so that the public would be ready for it. In the past, people washed by hand, used electric rotary washers, scythe and then electric mowers, kept money at home, and children played with plush toys made at home or bought in the shop. Over the last hundred years, there have been diametrical changes, but the society does not complain and accepts reality as it is, even wants to constantly develop. Probably soon there will be no money in circulation, the public will be afraid of reality, parcel lockers will speak to their owners at the time of getting the parcel, and the elders will treat Roomba robots as their own dogs that will feed crumbs, as in the film Man with magic box.

Every new technology (including robots) should be used properly. The erroneous use of what technology provides for development can lead to negative effects, and even involve the transfer of reality to the world of robots and the inability to return to the real world, the world of people.

The construction and functionality of robots finds their justification in the artificial intelligence on which it is based. Artificial intelligence creates models of intelligent behaviors and programs that these models simulate. Artificial intelligence, as a field of science, examines the mental behavior of man and the mechanism of their formation, and then using systems and computer programs recreates these behaviors, imitating human thinking. Its scope covers artificial life and robotics, using fuzzy logic, neural networks and evolutionary calculations (Kryszewski, 1984).

The basic reason for creating robots accompanying in everyday life was comfort and savings of human work. Initially, also humanoid robots (having human characteristics) were to help in the care of children, the elderly or disabled people, relieve people in certain duties and support in moments of fatigue. However, this idea did not fully work. Robots created on the basis of intelligent models keep being able to create their own artificial intelligence and use their own language that is unintelligible to mankind. Artificial intelligence exceeds human intelligence many times, it can play such a creative game as chess, anticipate behavior and 
constantly learn. Robots can communicate with each other and communicate with people. Respond to sent emails and questions. Nowadays, machines make more inquiries on the Internet than humans. In addition, robots are able to paint images and create music. There is a high probability that society does not fully trust robots, which, moreover, often repeat that they want to destroy humanity. Just like Sophia - the first robot to obtain the citizenship of any country, in this case Saudi Arabia. In one of the television programs after winding in the social game "Paper, stone, scissors" Sophia said it was the first step to mass destruction, and she smiled.

Sophia was produced in Hong Kong in 2017 and physically resembles a human. The robot tries to react to questions on its own, not using programmed responses. In addition, he imitates man very well and in the future he wants to have his own consciousness.

Saudi Arabia, granting citizenship to the robot, undoubtedly made a bold step towards the development of humanity and a broad view of reality. However, this fact raises a lot of controversy. First of all, that this happened in a country where women do not have civil rights, and secondly, how should authorities behave in a situation where someone deliberately destroys Sophi's software, will he murder in such a case and should be punished for that? On the other hand, the robot is unable to feel (at least at the contemporary level of development). There is no doubt that in the future probably many countries will decide to grant civil rights to robots.

In addition to the positive justification of the creature, the robots also have negative ones. As it turns out, men in Japan are looking for love and happiness among silicone dolls or robots. Women when they get pregnant cease to be lovers for their husbands. Spouses do not take divorces but live in one home and raise their children without being together.

Japanese dolls look like women. Men can paint them, change their heads to have different hair colors and facial features. It seems very real, therefore, the likelihood of the extinction of Japanese women. However, before this happens, if it happens at all, male dolls are created for atypical women of this nationality. It is frightening and up-to-date, however, that dolls are also created in the likeness of young children, so that the sexual benefits can be obtained by pedophiles. For those who like violence, puppets that put up sexual resistance are produced.

Where is ethics and reason in all this? After all, man is responsible for creating all sorts of robots. Unfortunately, he has already given direction and in the near future the society will reach the point of human technological development, in which technology will develop so quickly that people will not be able to influence it. This point is called social peculiarity. 


\section{Opportunities for the development of the world in the aspect of new technologies}

It is worth noting that if a person will be rational in approaching modern technologies and will not succumb to the evil created by the inventions of some technological creators, he can derive many benefits from some methods, systems or techniques.

New technologies mean the possibility of achieving previously non-existent possibilities. Man can obtain valuable information in a very short time, communicate with people from around the world, look for messages on every topic, make friends, use electronic mail, social networks and applications to send information about what is currently being done with the help of photos. New technologies are also a mine of music, films, forums with various collections of news and electronic books. It is also the speed and ease of moving people and things.

The advantage of new technologies is also that they adapt to the needs and influence economic development. In addition, new technologies affect comfort in everyday life and on the travel, make life seem easier, eg by listening to your favorite music from stressful duties. People who do not like to make phone calls have the ability to send messages through many instant messengers.

New technologies are also comfort and safety. Society does not have to worry about everyday activities, because a robot or other intelligent system will do it for them. The dynamic development of civilization promotes the growth of prosperity, self-fulfillment and selfdevelopment. People who have problems moving or who value peace and quiet can do the job remotely from the comfort of their home.

Another benefit is the extension of life expectancy, which is related to the development of medicine and other fields of science, the ability to shop online, security for which robots left in homes are responsible, the ease of banking transactions and general improvement and facilitation of functioning.

\section{Threats for the development of the world in the aspect of new technologies}

In addition to many advantages, new technologies have just as much or even more disadvantages. The primary threats to the development of the world in the aspect of new technologies include secondary illiteracy. This does not apply directly to the lack of writing or reading skills, although it may also be possible to do so by writing only on the keyboard of portable personal computers or telephones. Secondary illiteracy is mainly related to the problems of writing longer forms of expression or any own content, because everything can be 
"copied from the Internet", with understanding of the read content, eg literary works or user manuals, with analysis, reading data from the chart, finding a location on the map or orientation in the area because the satellite navigation system will show you the way. Secondary illiteracy, which can be encountered on a daily basis, is a problem with issuing the rest, counting in memory either in writing or filling out forms or making other formalities.

Other hazards caused by new technologies are those related to life and health: damage to the eyes, backache or damage to the spine, pains in wrists and toes, headaches, long-lasting migraines, psychological conditions or depression, radiation, tingling or limb numbness.

Total surveillance and loss of privacy is also a huge disadvantage of new technologies that are difficult to counter. All applications and devices collect data about who is located in the site, thematically sending profiles of potential friends or analogically display thematic websites or products that are likely to be in the area of interest. In addition, they constantly monitor the user's location, know who the person is with, who their friend is, what they are interested in, how they like to spend their free time, what music they like to listen to, what to read, what to watch, where to eat, what time they get up, which he falls asleep. All this data is analyzed and can be used in the process of identity theft or fraud. Easiness of access to data by third parties, it is also possible to modify or delete them, prevent access to some services or block them completely. In addition, every man has to have a chip in the form of a tattoo, which will also be a personal ID card, credit/debit card and keys to the apartment, and all this will be taken to one network. The amount of data to be analyzed will be huge, but also easy to steal. Among the dangers, the loneliness on the web is distinguished by a great threat to society. At that time, real contact with a long person was very important, the society talked about and spent time together. Nowadays, you can see how young people (their concerns the most) travel with headphones in listening to music, watching, playing, reading, all the time staring at the screens of smartphones, as if they were afraid of reality.

The relentless thing is that such behaviors are also transferred for moments when someone is alone. Instead of a moment of conversation, a smartphone is chosen, and there is always time for such entertainment, and no one will come back to talk. From such alienation comes psychological states or depression, a man does not know how to behave when he suddenly forgets the smartphone, where to look, how to talk. A social threat can also be called upbringing problems, destroying family foundations, lack of real time for entertainment and psychological activity, that is life in a virtual world, an imaginary world.

An important threat from the point of view of the development of society is actually its regress, or the disappearance of intelligence. Human skills that are not used disappear. If intelligent devices, houses, vehicles will think for a human, he will become somewhat limited and incapacitated, he will not be able to make any decisions. In addition, in the future, each person will have their own assistant who will replace the memory and say what needs to be done each day, where to go, how to behave. This will affect the loss of human value and increase the value of robots. 


\section{Summary}

New technologies cause many threats, but they are still being improved and implemented. They help to create the future reality, improve the comfort of life and increase the security, while depriving this security. Why are people unable to secure their existence and create a completely abstract reality? Nowadays, in order for something to influence a person, he must believe that a second person is behind it, how will he be in the future? A terrifying world or a good tool for improving life? Artificial intelligence is probably the last invention of humanity.

As long as people maintain control over the direction of development of new technologies, society should not be afraid. All that remains is to educate the public about the proper use of new technologies and accept that, over the years, the speed of human development is increasing.

\section{References}

1. Berger, P.L., Luckmann, T. (1983). Społeczne tworzenie rzeczywistości. Warszawa: Państwowy Instytut Wydawniczy.

2. Kryszewski, W. (ed.) (1984). Encyklopedia Powszechna PWN. Warszawa: PWN.

3. Praca zbiorowa (1996). Mała encyklopedia PWN. Warszawa: PWN.

4. Retkiewicz, W. (2013). Cyberprzestrzeń w geograficznych badaniach środowiska człowieka. Łódź: Wydawnictwo Uniwersytetu Łódzkiego.

5. Grzelak, M., Liedel, K. (2012). Bezpieczeństwo w cyberprzestrzeni. Zagrożenia i wyzwania dla Polski - zarys problemu. Bezpieczeństwo Narodowe, 22, II.

6. Znaki drogowe zasilane przez energię słoneczna (2018.12.12). https://edroga.pl/inzynieriaruchu/znaki-drogowe-zasilane-przez-energie-sloneczna-30119184. 